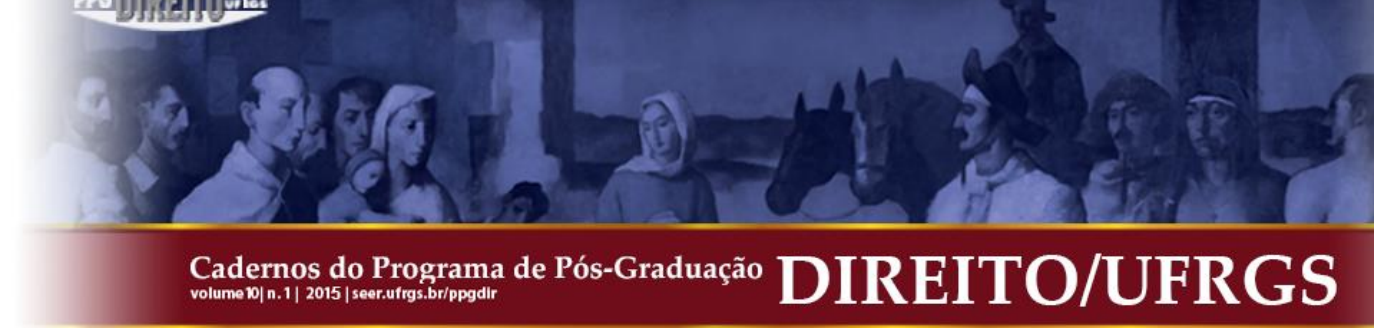

\title{
CONTRATO COM EFEITO PROTETIVO DE TERCEIROS, CULPA IN CONTRAHENDO E RESPONSABILIDADE DAS AGÊNCIAS DE RATING*
}

\author{
CONTRACT WITH PROTECTIVE EFFECT FOR THIRD PARTIES, CULPA IN CONTRA- \\ HENDO AND LIABILITY OF RATING AGENCIES
}

\section{Horst Hammen ${ }^{* *}$}

\begin{abstract}
RESUMO: O artigo trata da responsabilidade das agências de rating e, especialmente, da responsabilidade não contratual, resultante da falha na conclusão de um contrato (culpa in contrahendo) e de um contrato com efeito protetivo em benefício de terceiros. Neste contexto, a história e a dogmática dessas duas responsabilidades gerais foram detalhadamente descritas, com referência aos aspectos da jurisdição, jurisprudência e legislação. Especial atenção foi dada à explicação da origem da culpa in contrahendo por um dos mais populares juristas alemães, Rudolph v. Jhering, que se refere a partes do Direito Romano. Em seguida, mostrou-se que nem a culpa in contrahendo, nem o contrato com efeito protetivo em benefício de terceiros, indubitavelmente justifica uma responsabilidade das agências de rating frente aos investidores de capital. Como medidas apropriadas referentes à responsabilidade das agências de rating não estão disponíveis em todos os Estados Membros, em maio de 2013 a União Europeia editou uma responsabilidade das agências de rating por notações inadequadas frente a investidores, com aplicação em toda a Europa.
\end{abstract}

PALAVRAS-CHAVE: Agências de Rating. Responsabilidade por Violação de Dever. Culpa in Contrahendo. Contrato com Efeito Protetivo de Terceiros.
ABSTRACT: The paper deals with the liability of rating agencies and especially with the non-contractual li-ability resulting from fault in conclusion of a contract (culpa in contrahendo), and from a con-tract with protective effect to the benefit of third parties. In this context, the history and the dogmatic of these two general liabilities are being outlined in detail, with reference to the as-pects of jurisdiction, jurisprudence, and legislation. Special attention is being paid to the explication of the origin of culpa in contrahendo by one of the most popular German legal scholars, Rudolph $v$. Jhering, who refers to parts of the Roman law. Then, it is shown that neither the culpa in contrahendo, nor the contract with protective effect to the benefit of third parties, undoubtedly justify a liability of rating agencies toward capital investors. As appropriate measures on the liability of rating agencies are not available in all member states, in May 2013 the European Union Europe-wide has issued a liability of rating agencies for inadequate rat-ings toward investors.

KEYWORDS: Rating Agencies. Liability for Breach of Duty. Culpa in Contrahendo. Contract with Protective Effect to the Benefit of Third Parties.

SUMÁRIO: Introdução. 1. O que é rating? 2. Para que o rating é necessário? 3. Responsabilidade das agências de rating nos termos do direito alemão. 3.1. Desenvolvimento do problema. 3.2. Um resumo da história e da dogmática do contrato com efeito protetivo de terceiros. 3.3. Visão geral da história e da dogmática da doutrina da culpa in contrahendo. 3.4. Responsabilidade de especialista. 3.5. Contrato com efeito protetivo de terceiros e culpa in contrahendo por rating falho. 4. Responsabilidade das agências de rating nos termos do direito europeu. Considerações finais. Referências.

\section{INTRODUÇÃO}

A crise dos mercados financeiros e das dívidas estatais na Europa e nos Estados Unidos foi provocada por muitos e diferentes atores do mercado. Como causas concorrentes à crise, consideram-se as avaliações falsas de títulos bancários, realizadas pelas grandes agên-

\footnotetext{
* Palestra proferida em $1^{\circ}$ de abril de 2014, no Salão Nobre da Faculdade de Direito da Universidade Federal do Rio Grande do Sul, realizada no âmbito do programa de cooperação Giessen-UFRGS Probal II CAPES-DAAD, sob a coordenação do Prof. Dr. Augusto Jaeger Jr. Tradução de Felix Roman Wokittel, Doutorando DAADCAPES, Probal II, Giessen-UFRGS. Revisão de Kenny Sontag. Mantida a forma oral.

*** Professor de Direito Civil, de Direito Comercial e Econômico e de Direito Bancário e de Mercado de Capitais Alemão e Europeu da Justus-Liebig-Universität Gießen, Alemanha.
} 


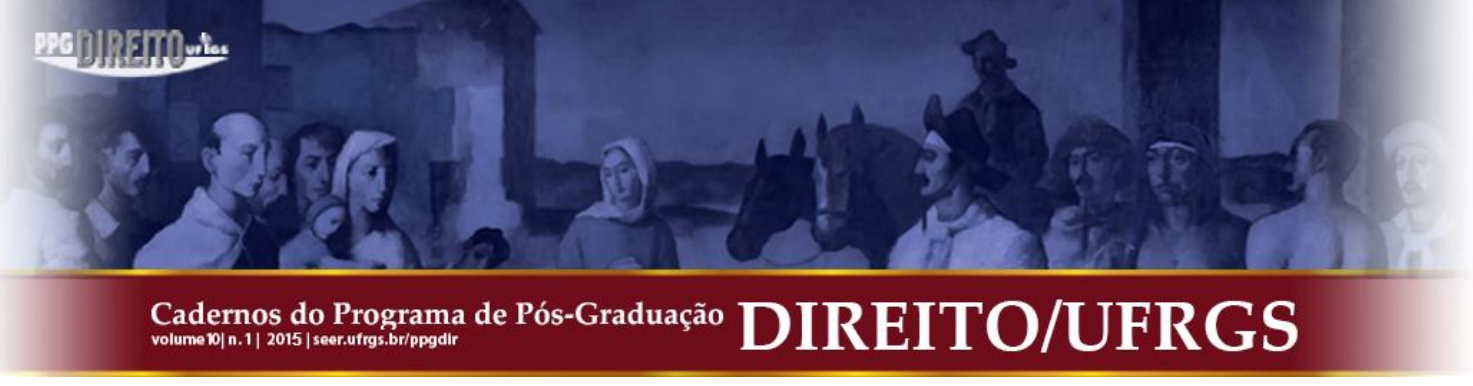

cias de Rating internacionais - Standard Poor's, Moody's e Fitch ${ }^{1}$. Essa circunstância motivou o Judiciário, bem como o legislador da União Europeia, a atuar. No ano passado, o Superior Tribunal Federal de Justiça da Alemanha (Bundesgerichtshof - BGH) aceitou várias ações de indenização de investidores privados, que tinham sofrido prejuízos causados pelos certificados do banco insolvente americano Lehmann Brothers, contra a agência Standard e Poor's, embora a agência tenha sua sede em Nova York². Em fevereiro de 2013, o Ministério da Justiça norte-americano acusou, em ação civil, a Standard \& Poor's de fraude, devido a uma avaliação conscientemente excessiva de títulos hipotecários subprime. Os pedidos de indenização do governo foram calculados na ordem de US\$ 5 bilhões ${ }^{3}$. Além disso, a União Europeia reagiu aos acontecimentos, já no fim de 2009, com um Regulamento especificamente adaptado para essas agências de Rating. ${ }^{4}$ Em maio de 2013, uma revisão deste Regulamento entrou em vigor ${ }^{5}$, concedendo, em circunstâncias determinadas, pedidos de indemnização contra agências de rating devido a avaliações incorretas a investidores. Essa questão e a discussão sobre a responsabilidade das agências de acordo com a lei alemã é o tema do presente trabalho.

\section{O QUE É RATING?}

Rating (ou classificação) designa, no contexto do direito bancário e de mercado de capitais, a avaliação da probabilidade de execução contratual das obrigações de pagamento de títulos da dívida pública, títulos bancários, títulos corporativos e empréstimos. Em outras pa-

\footnotetext{
${ }^{1}$ HAAR, Brigitte. Haftung für fehlerhafte Ratings von Lehman-Zertifikaten: Ein neuer Baustein für ein verbessertes Regulierungsdesign im Ratingsektor? Neue Zeitschrift für Gesellschaftsrecht (NZG), Heft 33, 2010, p. 1281 .

2 Vide jurisprudência BGH, 13.12.2012 - III ZR 282/11: Vermögensgerichtsstand bei inländischem Klägerwohnsitz, publicada em Neue Juristische Wochenschrift (NJW), Heft 6, 2013, p. 386; BGH, 12.12.2012 VIII ZR 307/11: Wirksame Klagezustellung trotz fehlender Anlagen (m. Anm. Schäfer), publicada em Neue Juristische Wochenschrift (NJW), Heft 6, 2013, p. 387; OLG Frankfurt a.M. (Oberlandesgericht Frankfurt am Main), 28.11.2011: Zur örtlichen gerichtlichen Zuständigkeit für die Klage eines Kapitalanlegers gegen eine Rating-Agentur mit Sitz in New York auf Schadensersatz wegen Insolvenz einer mit A+ bewerteten Emittentin, publicada em Zeitschrift für Wirtschafts- und Bankrecht (WM), n. 50-52, 2011, p. 2360. Vide também o andamento do processo OLG Frankfurt a.M., 30.12.2013, 21 U 23/11.

${ }^{3}$ HAAR, Brigitte. Neues zur Haftung von Ratingagenturen im Zuge der zweiten Novelle der Rating-Verordnung (CRA III)? Der Betrieb (DB), Heft 44, 2013, p. 2489, 2491 e ss.

${ }^{4}$ UNIÃO EUROPEIA, Regulamento (CE) N ${ }^{\circ}$ 1060/2009, de 16 de setembro de 2009, sobre agências de rating.

${ }^{5}$ UNIÃO EUROPEIA, Regulamento (UE) No 462/2013, de 21 de maio de 2013, em modificação ao Regulamento (CE) $\mathrm{N}^{\circ} 1060 / 2009$, de 16 de setembro de 2009 , sobre agências de rating.
} 


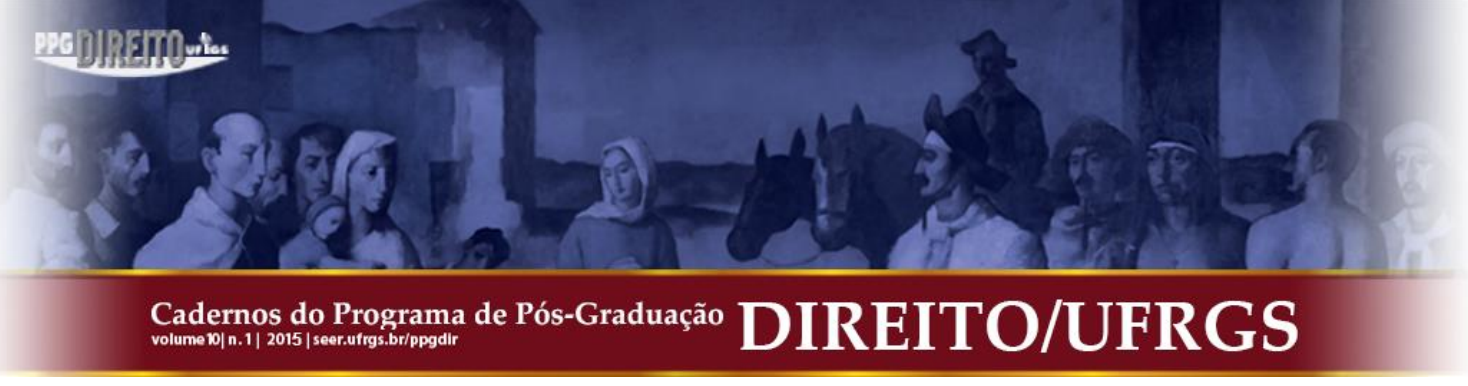

lavras, trata-se da credibilidade do emitente ou do devedor ${ }^{6}$. Ratings são baseadas em fatores quantitativos e qualitativos. A abordagem quantitativa leva a uma avaliação da situação econômica do emitente, levando em conta sua liquidez, o resultado de suas operações e sua estrutura de capital, com base em indicadores de balanço patrimonial, como lucros e quota de capital próprio. Os fatores qualitativos incluem caraterísticas tais como a qualidade da gestão, a estratégia empresarial, o potencial de recursos humanos e a gestão de riscos ${ }^{7}$.

As agências de rating expõem o risco de inadimplemento do devedor por meio de um código de classificação. Para a Standard \& Poor's, esse código, em caso de ratings de longo prazo, varia de AAA (muito seguro) para D (em inadimplência). Ratings entre AAA e BBB são considerados como nível de investimento e entre BB+ e D como nível de subinvestimento. Eu ainda me recordo muito bem de minha visita a Porto Alegre, em 2008, quando pude compartilhar convosco a alegria da atribuição de nível de investimento ao Brasil pela Standard \& Poor's e Fitch em abril e maio daquele ano. Em novembro de 2011, a Standard \& Poor's elevou o rating do Brasil de BBB- para BBB. No momento, o rating do Brasil pelas agências americanas de rating está sob pressão ${ }^{8}$. Portanto, talvez seja interessante observar que a agência de rating chinesa Dagong, que criou os seus ratings sob a perspectiva dos BRICs, ainda avalia o Brasil como A- ${ }^{9}$.

\section{PARA QUE O RATING É NECESSÁRIO?}

De fato, não há na legislação europeia a imposição legal de os emissores obterem uma classificação dos valores mobiliários relevantes antes da sua admissão à negociação na bolsa de valores. E também não existe nenhum dever geral prudencial das instituições financeiras ou investidores em investir apenas em títulos que tenham sido objeto de uma classificação ${ }^{10}$. Entretanto, o emissor tem um interesse próprio em uma classificação, pois, frequentemente, só tem a chance de colocar seus títulos no mercado de capitais se há uma classificação para is-

\footnotetext{
${ }^{6}$ HENNRICHS, Joachim. Haftungsrechtliche Aspekte des Ratings. In: HÄUSER, Franz; HAMMEN, Horst et al (Hrsg.). Festschrift für Walther Hadding zum 70. Geburtstag. Berlin: De Gruyter, 2004, p. 875, com nota de rodapé 1.

${ }^{7}$ Disponível em <http://de.wikipedia.org/wiki/Rating>. Acesso em: 12 de maio de 2014.

${ }^{8}$ ZSCHÄPITZ, Holger. Brasiliens Staatsschulden ruinieren die BRIC-Story. Die Welt, Berlin, 26 mar. 2014. Geld, p. 15.

${ }^{9}$ Sobre fatores culturais que influenciam o rating de países, vide FUCHS, Andreas; GEHRING, Kai. Kulturelle Faktoren beeinflussen die Länderratings vielfach unbewusst. Börsen-Zeitung, Frankfurt a.M., n. 29,12 fev. 2014, p. 6.

${ }^{10}$ UNIÃO EUROPEIA, Regulamento (CE) N 1060/2009 sobre agências de rating, de 16 de setembro de 2009, considerações 3 e 4.
} 


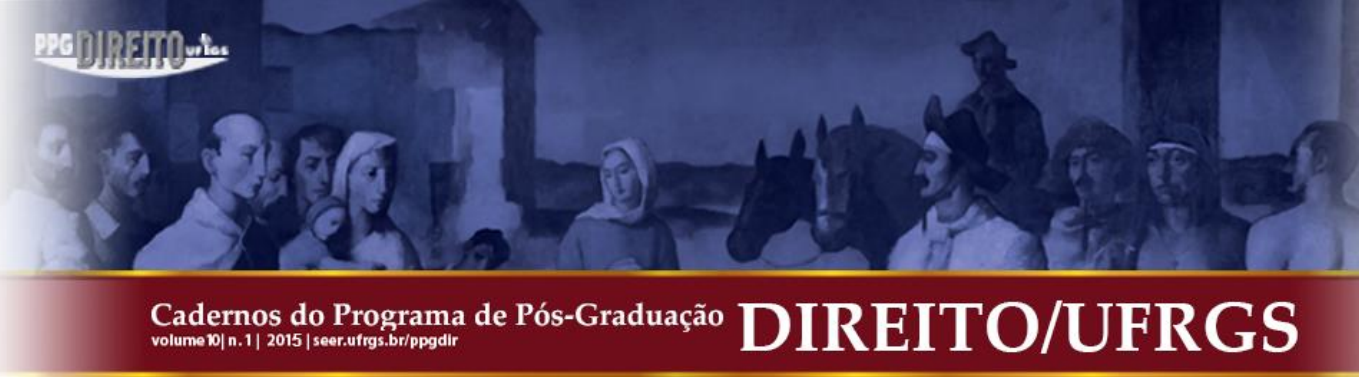

so. Por parte dos investidores, existe um interesse em classificações porque os órgãos gestores do investidor, que investem em títulos, devem verificar a probabilidade de inadimplemento do emitente.

Uma avaliação da probabilidade de inadimplemento por meio de um próprio departamento de pesquisa dos investidores é, geralmente, excessivamente cara. Portanto, empresas especializadas - as agências de rating - operam no mercado, contribuindo como intermediárias de informações, por meio da publicação de classificações, reduzindo as assimetrias de informação e, assim, colaborando para a eficiência dos mercados de capitais, na medida em que fornecem aos investidores institucionais e privados uma avaliação da probabilidade de inadimplemento de um emitente, diminuindo, desse modo, os custos de transação para os investidores ${ }^{11}$.

\section{RESPONSABILIDADE DAS AGÊNCIAS DE RATING NOS TERMOS DO DIREI- TO ALEMÃO}

\subsection{Desenvolvimento do Problema}

No caso de uma classificação ter sido errônea, por exemplo, porque um título foi classificado muito alto, deve-se verificar se os investidores ${ }^{12}$, que investiram em um desses títulos, podem requerer indenização contra a agência de rating em causa. Originalmente, o regulamento sobre agências de rating da União Europeia, mencionado acima, não continha regras relativas à responsabilidade das agências em relação aos investidores. Portanto, apenas as legislações dos Estados-membros da União Europeia foram decisivas para esta responsabilização. De acordo com a lei alemã, a responsabilidade de indenização das agências de rating considera a prática de ato ilícito ou de violação de obrigações contratuais ou pré-contratuais das agências. Neste contexto, uma proteção delitual dos investidores pode ser rapidamente afastada. Pois o direito alemão exige, para uma responsabilização delitual, a interferência na propriedade ou em um direito similarmente estruturado (cf. §823, Abs. 1 BGB). Um puro dano ao patrimônio, como o que normalmente decorre de uma decisão de investimento com base

11 BURGHOF, Hans-Peter; SCHNEIDER, Johannes; WENGNER, Andreas. Der Informationsgehalt von Ratingänderungen für US- und europäische Unternehmen - Eine empirische Analyse. Zeitschrift für Bankrecht und Bankwirtschaft (ZBB), Heft 3, 2013, p. 171; também sobre as reações do mercado quanto às modificações de rating.

${ }^{12}$ A responsabilidade da agência de rating frente ao emitente permanece excluída.

Cadernos do Programa de Pós-Graduação em Direito PPGDir./UFRGS | Edição Digital | Porto Alegre | Volume X | Número 1 | 2015 | P.68 - 93 


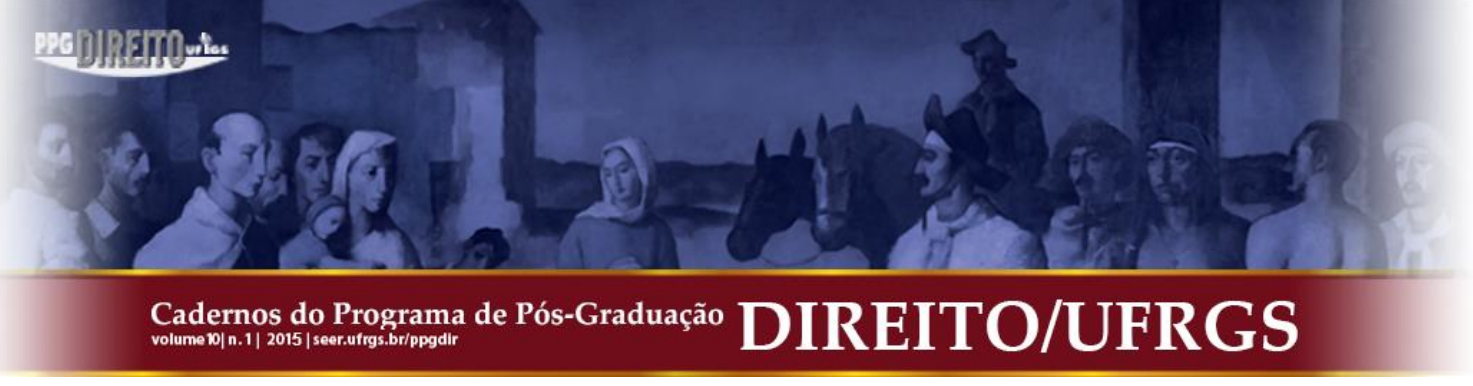

em uma classificação incorreta, não é suficiente ${ }^{13}$. Obviamente a legislação alemã conhece a responsabilidade devido à violação de obrigações contratuais ( $\$ 280$ e segs. BGB). Por causa disso, quando suprido de classificações baseadas em um contrato de subscrição com a agência de rating, um investidor, que toma uma decisão de investimento com base numa classificação deficitária, adquire a pretensão de indenização, devido à violação contratual (violação de dever).

A situação jurídica é mais complicada se não há relação contratual entre a agência de rating e um investidor, ou, em termos mais gerais, se os envolvidos se encontram num âmbito extra ou pré-contratual. $\mathrm{O}$ direito alemão reconhece dois institutos jurídicos utilizados para a proteção não delitual de pessoas não vinculadas a um contrato ou, em todo caso, a um contrato eficaz, designadamente:

- o contrato com efeito protetivo de terceiros e

- a obrigação pré-contratual do $\$ 311$, Abs. 2 e 3 BGB.

No direito brasileiro, existe também uma responsabilidade relativa a terceiros na fase pré-contratual. Embora isto não seja expressamente disposto, mas estabelecido indiretamente no artigo 422 do Código Civil de 2002. Essa responsabilidade foi baseada no explicitamente previsto princípio da boa fé ${ }^{14}$. O princípio da boa-fé também não é desconhecido para o direito alemão. Aqui, no entanto, tendo em vista a concepção legal do §242 BGB, ele só incide em uma relação obrigacional pré-existente. Portanto, a dogmática jurídica alemã, no desenvolvimento da área pré-contratual ou das relações com terceiros, seguiu um caminho diferente do direito brasileiro. Para se traçar a história dogmática deste desenvolvimento, sujeita-se às observações seguintes.

\subsection{Um Resumo da História e da Dogmática do Contrato com Efeito Protetivo de Ter- ceiros}

Basicamente, contratos de eficácia obrigacional, que são celebrados em nome próprio, atuam apenas na relação entre as partes contratantes. Contratos destinados a estabelecer relações jurídicas com terceiros não envolvidos na transação são, a princípio, inconsistentes com a liberdade contratual deste terceiro. Por causa disso, os contratos destinados a impor obriga-

\footnotetext{
${ }^{13}$ HAAR, Brigitte. op. cit. (NZG, 2010), p. 1281-1285; WOJCIK, Karl-Philipp. Zivilrechtliche Haftung von Ratingagenturen nach europäischem Recht. Neue Juristische Wochenschrift (NJW), Heft 33, 2013, p. 2385-2386.

${ }^{14}$ Esta informação me foi transmitida pela estudante de direito Senhora Marjorie Cavalli Renner. 


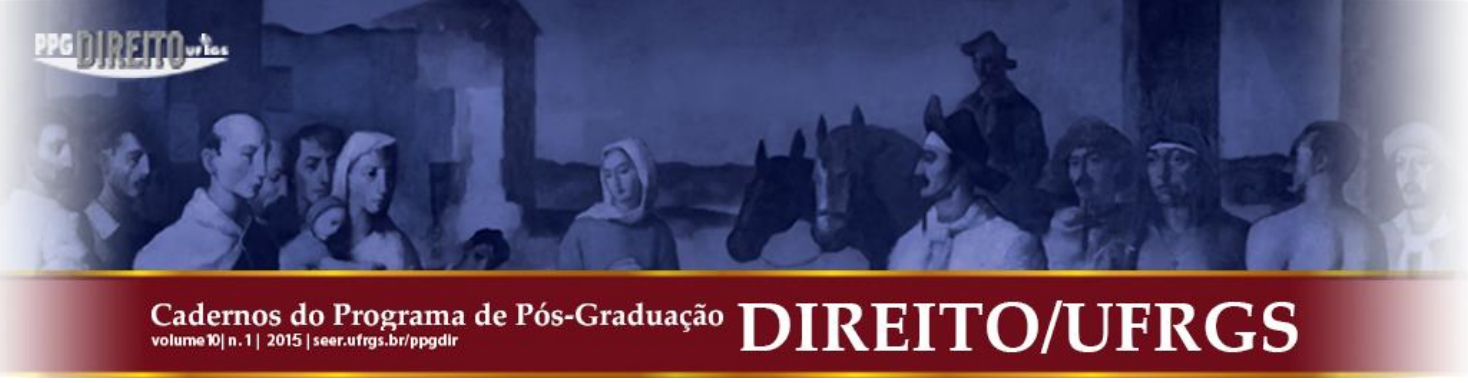

ções a um terceiro (contratos em detrimento de terceiros), são, em qualquer caso, ineficazes. A situação de contratos que confiram um direito a um terceiro é diferente. Enquanto, nos termos do direito romano, tais contratos eram, à parte os casos excepcionais, ineficazes ${ }^{15}$, o direito civil alemão permite, explicitamente, contratos em que um terceiro adquire diretamente o direito de demandar uma prestação ( $\$ 328$, Abs. 1 BGB), se não rejeita a aquisição ( $\$ 333$ BGB $)^{16}$. Como exemplo, que teria levado os autores do código civil a se desviarem do direito romano, indica-se o contrato de seguro de vida em benefício de terceiros ${ }^{17}$.

Logo após a entrada em vigor do código civil, o Tribunal Imperial (Reichsgericht) começou a permitir que terceiros, que não eram partes de um contrato, participassem dos efeitos jurídicos desse contrato. Impulso à formatação do contrato com efeito protetivo de terceiros e ocasião para a não fundamentação na doutrina da culpa in contrahendo, mas para a sua extensão especificamente aos casos chamados de responsabilidade de especialista, foi a avaliação de que o direito delitual (Deliktsrecht), em muitos casos, era insuficiente para proteger as vítimas. De fato, a responsabilidade de ajudante do $\$ 831$ BGB foi inadequadamente equipada com as suas amplas possibilidades de exoneração. Também há ausência de uma reponsabilidade delitual geral para danos patrimoniais puros, já que o §823, Abs. 1 BGB exige a violação de um direito absoluto da parte lesada. Por fim, ao lesado é atribuído completamente o ônus da prova, diferentemente do caso da violação de uma relação obrigacional (\$280, Abs. 1, S. 2 $\mathrm{BGB})^{18}$.

Inicialmente, a base jurídica para uma proteção de terceiros foi procurada no $§ 328$ BGB. Em primeiro lugar, o Tribunal Imperial determinou, sem levar em conta o conteúdo das cláusulas contratuais, em um caso de contrato de transporte, que o consumidor contratasse

15 STAUDINGER, Julius von. Kommentar zum Bürgerlichen Gesetzbuch mit Einführungsgesetz und Nebengesetzen: BGB. Buch 2. Neubearbeitung von Rainer Jagmann und Volker Rieble. Redaktor Manfred Löwisch. Berlin: Walter de Gruyter, 2009, observação preliminar dos $\S 328$ e ss, ponto 8.

16 Sobre a interpretação desta norma, vide SOERGEL, Hans-Theodor. Bürgerliches Gesetzbuch mit Einführungsgesetz und Nebengesetzen: BGB. 13. Auflage. Band 5/3. Bearbeitet von Martin Gebauer, Walther Hadding, Walter Lindacher, Thomas lobinger, Thomas Pfeiffer sowie Klaus Schreiber. Stuttgart: Kohlhammer, 2010, §328, pontos 10-13.

${ }^{17}$ MUGDAN, Benno. Die gesammten Materialien zum Bürgerlichen Gesetzbuch für das Deutsche Reich. Band I. Berlin: R. v. Decker, 1899, p. 147.

18 Vide RGZ 65, 17 (19); RGZ 95, 58 (60); RGZ 98, 210 (211 e ss); WarnRspr. 1919 Nr. 14; SOERGEL, HansTheodor. op. cit., §328, ponto 1, sobre o contrato com efeito protetivo de terceiro; comentário de Volker Emmerich em SÄCKER, Franz Jürgen; RIXECKER, Roland; OETKER, Hartmut (Hrsg.). Münchener Kommentar zum Bürgerlichen Gesetzbuch. 6. Auflage. Band 2. München: C. H. Beck, 2012, §311, ponto 38, com nota de rodapé 11 , sobre a culpa in contrahendo. Além disso, antigamente, aplicavam-se prazos de prescrição mais curtos aos delitos (\$852 BGB versão antiga) do que às reclamações de indenização por danos segundo direito geral das obrigações ( $\$ 195$ BGB versão antiga), vide LORENZ, Werner. Die Einbeziehung Dritter in vertragliche Schuldverhältnisse: Grenzen zwischen vertraglicher und deliktischer Haftung. Juristenzeitung (JZ), Band 15, 1960, p. 108-109.

Cadernos do Programa de Pós-Graduação em Direito PPGDir./UFRGS | Edição Digital | Porto Alegre | Volume X | Número 1 | 2015 | P.68 - 93 


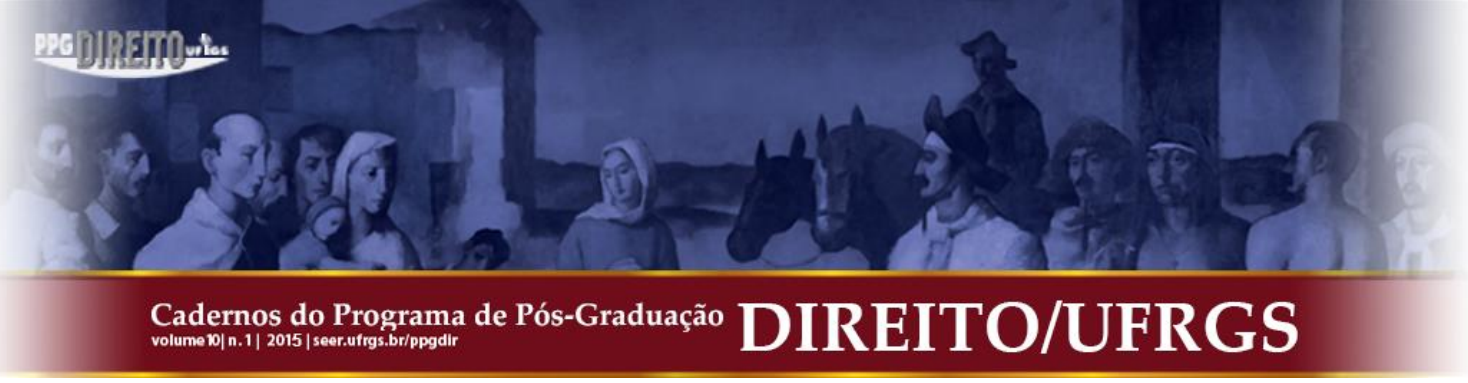

concomitante a favor dos seus acompanhantes, adquirindo estes como terceiros, segundo $§ 328$ BGB, o direito de demandar um transporte regular e seguro ${ }^{19}$. Logo após, o Tribunal Imperial manifestou uma obrigação de indenizar terceiros, proveniente do contrato, independentemente destes terem legitimidade, frente ao promitente, para reclamar uma prestação contratual ${ }^{20}$. O Tribunal destacou o tipo de efeitos jurídicos aos terceiros ainda mais claramente, expressando tratar-se de uma reivindicação contra a violação de um "dever de cuidado", com base no $§ 328$ $\mathrm{BGB}^{21}$. É claro que várias objeções foram manifestadas contra a referência ao §328 BGB. Esta disposição exigia - dizia-se - o fundamento de direitos a prestações, designadamente reclamações referentes à prestação principal devida, o qual o terceiro não tem no caso de contrato com efeito protetivo de terceiros, pois tem apenas resguardo contra uma violação de proteção $^{22}$. Portanto, a conexão com o $\$ 328$ BGB foi abandonada ${ }^{23}$. Agora, tem-se ensinado entre outros - que o contrato com efeito protetivo de terceiros é um tipo contratual próprio ${ }^{24}$. Isso levantou a questão do fundamento jurídico para essa opinião. Provavelmente, o Tribunal Imperial se pronunciou pela primeira vez sobre a questão de como o terceiro será incluído na estrutura dos deveres do contrato em RGZ 91, 21 (23). O Tribunal queria dar a esta inclusão um fundamento contratual ${ }^{25}$ e opinou que deveria o promissário estar "subordinado" à reconhecível intenção do promitente de considerar os interesses do terceiro no momento de conclusão do contrato. Logo após, o Tribunal Imperial falou de um "acordo tácito" sobre a inclusão do terceiro ${ }^{26}$. Agora, a aceitação de um acordo tácito a favor de terceiros é admitida sem maiores percalços, havendo correspondentes e determinadas circunstâncias ${ }^{27}$. E, em virtude da liberdade contratual, isto também é válido quando, segundo o conteúdo do contrato, não se

\footnotetext{
${ }^{19}$ RGZ 87, 64 (65).

${ }^{20}$ RGZ 87, 289 (292 e ss.)

${ }^{21}$ RGZ 102, 231 (232).

22 BGH, 25.4.1956 - VI ZR 34/55: Lieferungsvertrag zugunsten Bediensteter des Bestellers (m. Anm. Larenz), publicado em Neue Juristische Wochenschrift (NJW), Heft 33, 1956, p. 1193; vide jurisprudência em Neue Juristische Wochenschrift (NJW), Heft 1/2, 1960, p. 78 e ss.; e comentário de Peter Gottwald em SÄCKER, Franz Jürgen; RIXECKER, Roland; OETKER, Hartmut (Hrsg.). op. cit. (2012), §328, ponto 164.

23 BGH, 15.5.1959 - VI ZR 109/58: Vertragsschutz dritter Personen, publicado em Neue Juristische Wochenschrift (NJW), Heft 38, 1959, p. 1676.

${ }^{24}$ Comentário de Peter Gottwald em SÄCKER, Franz Jürgen; RIXECKER, Roland; OETKER, Hartmut (Hrsg.). Münchener Kommentar zum Bürgerlichen Gesetzbuch. 4. Auflage. Band 2-A. München: C. H. Beck, 2003, $\S 328$, ponto 100 .

${ }^{25}$ RGZ 102, 231 (232): "pretensão diretamente contratual".

${ }^{26}$ RGZ 98, 210 (212); RGZ 127, 218 (222).

27 ZIEGLER, Hans-Berndt. Verträge mit Schutzwirkung zugunsten Dritter? Marburg (Lahn): PhilippsUniversität Marburg, Dissertação, 1978, p. 80 e ss; porém, apenas no caso em que uma reivindicação principal também em benefício do terceiro foi justificada.
}

Cadernos do Programa de Pós-Graduação em Direito PPGDir./UFRGS | Edição Digital | Porto Alegre | Volume X | Número 1 | 2015 | P.68 - 93 


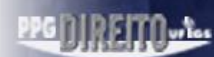

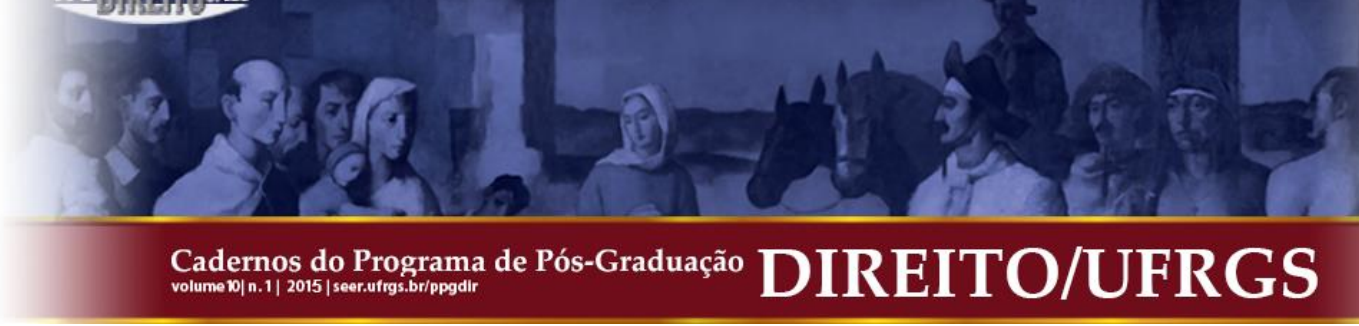

extracontratual, que não se enquadraria em um contrato (com efeito protetivo de terceiros) ${ }^{42}$. De qualquer modo, em todo caso, a lei ainda não contém uma regra sobre os pré-requisitos de um efeito protetivo de terceiros ${ }^{43}$.

\subsection{Visão Geral da História e da Dogmática da Doutrina da Culpa in Contrahendo}

Ocasionalmente, há casos em que um dano é causado sem desencadear uma efetiva ou até mesmo qualquer tipo de conclusão contratual. Um exemplo: $\mathrm{K}$, que gostaria de comprar um determinado automóvel usado de $\mathrm{V}$, faz antes um test drive com este carro. No caminho, o automóvel para por causa de um defeito. K precisa retornar de táxi e, portanto, gasta 100 eu$\operatorname{ros}^{44}$. Para lidar com a questão se um lesado - nesta ou em situação semelhante - pode exigir indenização, foi desenvolvido na Alemanha o instituto jurídico da cupla in contrahendo.

O início da doutrina da culpa in contrahendo está ligado desde sempre ao nome de Rudolf von Jhering (1818-1892) ${ }^{45}$, que tem uma interessante conexão com o Brasil, porque seu filho mais velho, Hermann von Jhering (1850-1930), viveu no Brasil por quarenta anos entre 1880 e 1920 - e foi fundador e primeiro diretor do Museu Paulista (Museu do Ipiranga), em São Paulo. Sobre Rudolf von Jhering, foi dito que "ele animou os ossos secos do direito romano"46. Com seu ensaio Culpa in Contrahendo ou Indenização em Contratos nulos ou não chegados à Perfeição ${ }^{47}$, por ele escrito no ano de 1861, enquanto lecionava na Universidade de Gießen, iniciou um desenvolvimento, até hoje não concluído. O ponto de partida para sua teoria, que afirmava a possibilidade de existência de uma "ação contratual à indenização por dano" ("dano, (...) que a celebração do contrato causou", "interesse contratual negativo") devido à "culpa cometida por ocasião de uma relação contratual pretendida" ("culpa in contrahendo"), foi a determinação do Direito Romano (Comum), então subsidiariamente aplicável na Alemanha, em Digesto 18.4.8 e $9^{48}$. De acordo com estas prescrições, o comprador de uma

\footnotetext{
${ }^{42}$ SOERGEL, Hans-Theodor. op. cit., $\$ 328$, ponto 5.

${ }^{43}$ STAUDINGER, Julius von. op. cit. (2009), §328, ponto 92.

${ }^{44}$ Exemplo em BROX, Hans; WALKER, Wolf-Dietrich. op. cit., §5, p. 63, ponto 1.

${ }^{45}$ KINDEREIT, Kai. Wer fühlt nicht, dass es hier einer Schadensersatzklage bedarf - Rudolf von Jhering und die „culpa in contrahendo“. In: Hoeren, Thomas (Hrsg.). Zivilrechtliche Entdecker. München: C. H. Beck, 2001, p. 73 e ss.

${ }^{46}$ Disponível em <http://en.wikipedia.org/wiki/rudolf_von_jhering>. Acesso em: 12.05.2014.

47 JHERING, Rudolf von. Culpa in contrahendo oder Schadensersatz bei nichtigen oder nicht zur Perfection gelangten Verträgen. Jahrbücher für die Dogmatik des heutigen römischen und deutschen Privatrechts. Band IV. Herausgegeben von C. F. von Gerber und R. Jhering. Jena: Friedrich Mauke, 1861, p. 1 e ss. seguintes.

48 JHERING, Rudolf von. op. cit., p. 3, 7, 15, 16, 19, 27.
} 


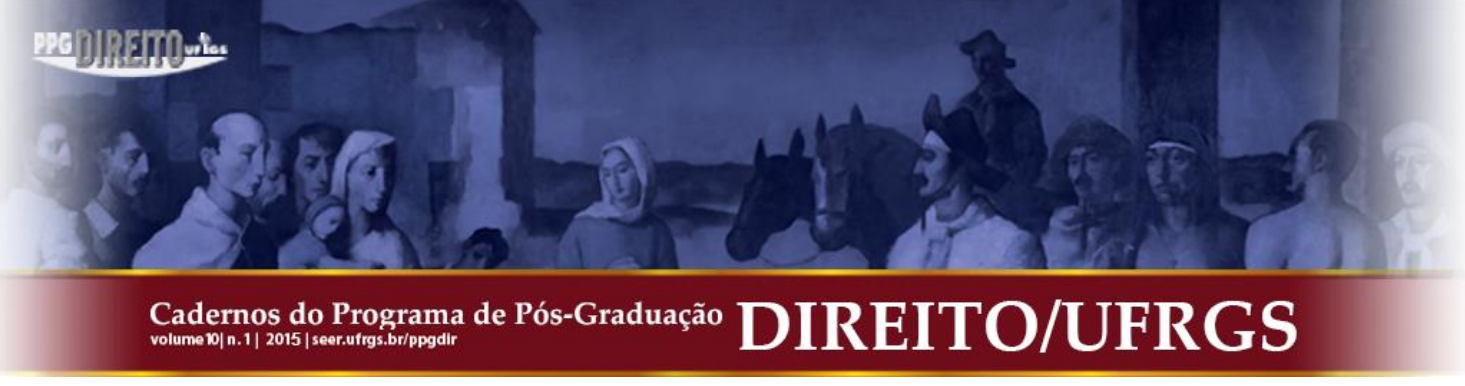

ção, independentemente de o contrato, posteriormente, realizar-se ou não ${ }^{77}$. Se não este contrato, então o que originaria esses deveres? Inicialmente, o Tribunal Imperial recorreu à ideia de um contrato tacitamente acordado, que deveria preparar a celebração do contrato de fato pretendido $^{78}$. Obviamente, tal acordo tácito, projetado especialmente para a fase de contatos preparatórios ao contrato, é prontamente possível, do mesmo modo que um acordo expresso correspondente $^{79}$, como uma letter of intent ou um memorandum of understanding. A jurisprudência enfrentou, posteriormente, a acusação suscitada, de fato justificável, de que tal contrato preparatório seria via de regra uma pura ficção ${ }^{80}$, com um distanciamento da culpa in contrahendo de categorias contratuais. Este distanciamento foi iniciado devido à constatação de que a culpa in contrahendo seria "semelhante ao contrato" ${ }^{81}$, pois uma relação jurídica meramente semelhante ao contrato não é precisamente uma relação contratual. Em RGZ 107, 357 (362), o Tribunal Imperial invocou um dos pensamentos jurídicos subjacentes nos $§ \S 179$, 307, 309, 694 BGB, o qual - porque seria indispensável às transações negociais - deveria ser aplicado também a outras situações, que seriam bastante semelhantes aos casos previstos em lei. Em RGZ 120, 126 (133), o Tribunal exprimiu, então, de modo metodicamente claro, uma analogia jurídica. Contra isso, entretanto, opôs-se o argumento de que as determinações legislativas $(\$ \S 122,179,307 \text { BGB versão antiga })^{82}$, geralmente mencionadas no âmbito da responsabilidade pré-contratual, são tão esporádicas e suas formas tão diferentes ${ }^{83}$, que uma analogia geral não seria possível ${ }^{84}$. A separação da culpa in contrahendo das categorias contratuais foi concluída, quando o BGH finalmente descreveu a culpa in contrahendo como uma relação obrigacional legal, em complemento ao do Direito escrito ${ }^{85}$. Quem, entretanto, teria estabelecido essa relação jurídica, não sendo o legislador, o BGH não revelou. Mais tarde, referiu-se a

\footnotetext{
77 RGZ 107, 357 (362); comentário de Volker Emmerich em SÄCKER, Franz Jürgen; RIXECKER, Roland; OETKER, Hartmut (Hrsg.). op. cit. (2012), §311, ponto 38, nota de rodapé 112.

${ }^{78}$ RGZ 65, 17, (19); GERNHUBER, Joachim (Hrsg.). op. cit., §8, I 4, p. 176.

${ }^{79}$ WOLF, Ernst. Lehrbuch des Schuldrechts. Band 1. Allgemeiner Teil. Köln: C. Heymann, 1978, §9 J, p. 509 e ss.; VAN GELDER, Alfons. op. cit., p. 1253-1254.

${ }^{80}$ STOLL, Heinrich. Haftung für das Verhalten während der Vertragsverhandlungen. Leipziger Zeitschrift für Handels-, Konkurs- und Versicherungsrecht (LZ), Band 17, 1923, p. 543.

${ }^{81}$ RGZ 78, 239 (240): “uma relação jurídica preparatória à compra (...), que apresenta um caráter semelhante ao contrato"; comentário de Volker Emmerich em SÄCKER, Franz Jürgen; RIXECKER, Roland; OETKER, Hartmut (Hrsg.). op. cit. (2012), §311, ponto 38, nota de rodapé 112. Vide também o título do §311, Abs. 2, 3 BGB: "relação obrigacional semelhante a negócio jurídico".

82 Vide BROX, Hans; WALKER, Wolf-Dietrich. op. cit., §5 I, p. 378.

$83 \S 122$ BGB: responsabilidade objetiva; $\$ 179$, Abs. 1 BGB: responsabilidade pelo interesse de cumprimento.

${ }^{84}$ LARENZ, Karl. Lehrbuch des Schuldrechts. 14. Auflage. Band I. Allgemeiner Teil. München: C. H. Beck, 1987, §9, I, p. 107; WOLF, Ernst. op. cit. (1978), §9 J, p. 513.

${ }^{85}$ BGHZ 6, 330, 333.
}

Cadernos do Programa de Pós-Graduação em Direito PPGDir./UFRGS | Edição Digital | Porto Alegre | Volume X | Número 1 | 2015 | P.68 - 93 


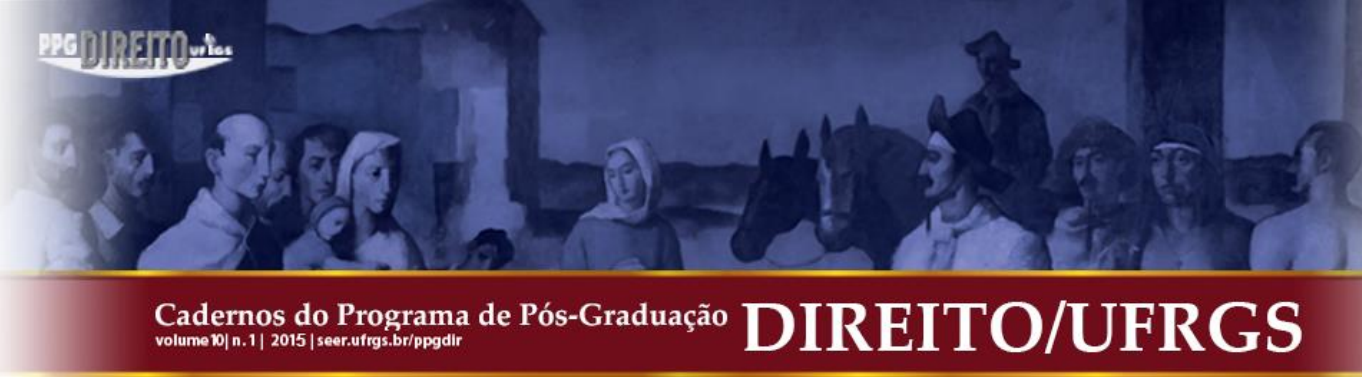

disposições legais", no entanto, também foi expressão incluída em 2002 na disposição do $\S 311$, Abs. 2 e 3 BGB sobre a culpa in contrahendo ${ }^{90}$.

Notável é que a então responsabilidade por interesse negativo pela impossibilidade inicial (\$307 BGB versão antiga), ou seja, o núcleo romano-jurídico da doutrina da culpa in contrahendo de von Jehring, foi removida e substituída por uma responsabilidade contratual pelo interesse de cumprimento ( $\$ 311 \mathrm{BGB})$.

\subsection{Responsabilidade de Especialista}

Nas últimas décadas, há nas tendências jurisprudenciais o uso do contrato com efeito protetivo de terceiros e a culpa in contrahendo como instrumentos para fundamentação de uma responsabilidade extradelitual de especialista. Um caso formulado a partir das categorias do contrato com efeito protetivo de terceiros, relacionado a uma das responsabilidades de agências de rating, é a responsabilidade de um perito por erro na avaliação de um imóvel, quando o parecer dado, encomendado pelo vendedor ao perito, é destinado ao uso frente ao comprador ou um credor ${ }^{91}$. Outro se refere à responsabilidade de um auditor frente a uma instituição creditícia que concede um empréstimo a um cliente bancário, com base em um relatório do auditor encomendado pelo cliente sobre o risco de crédito do cliente ${ }^{92}$. Um caso fundado nos princípios da culpa in contrahendo é constituído pela responsabilidade pelo prospecto (Prospekthaftung), baseada no direito civil geral não escrito, quando uma personalidade conhecida, que toma para si a pretensão de ter conhecimentos especiais, oferece informações errôneas sobre um investimento em um prospecto ${ }^{93}$.

\subsection{Contrato com Efeito Protetivo de Terceiros e culpa in contrahendo por Rating Falho}

\footnotetext{
${ }^{90}$ Comentário de Detlev Fischer em BAMBERGER, Heinz Georg; ROTH, Herbert. BGB. Beck'scher OnlineKommentar (1.11.2013). München: C. H. Beck, 2013, §675, ponto 91.

${ }^{91}$ BGHZ 159, p. 1 e ss.

92 BGH, 19.3.1986 - IVa ZR 127/84: Zur Berufshaftung von Wirtschaftsprüfern (BGB $\S \S 826,328,133,157)$, publicado em Juristenzeitung (JZ), Band 41, 1986, p. 1111.

93 BGH, 17.11.2011 - III ZR 103/10: Prospekthaftung eines früheren Spitzenpolitikers wegen werbender Aussagen in der Produktinformation, publicado em Neue Juristische Wochenschrift (NJW), Heft 11, 2012, p. 758.

Cadernos do Programa de Pós-Graduação em Direito PPGDir./UFRgS | Edição Digital | Porto Alegre | Volume X | Número 1 | 2015 | P.68 - 93
} 


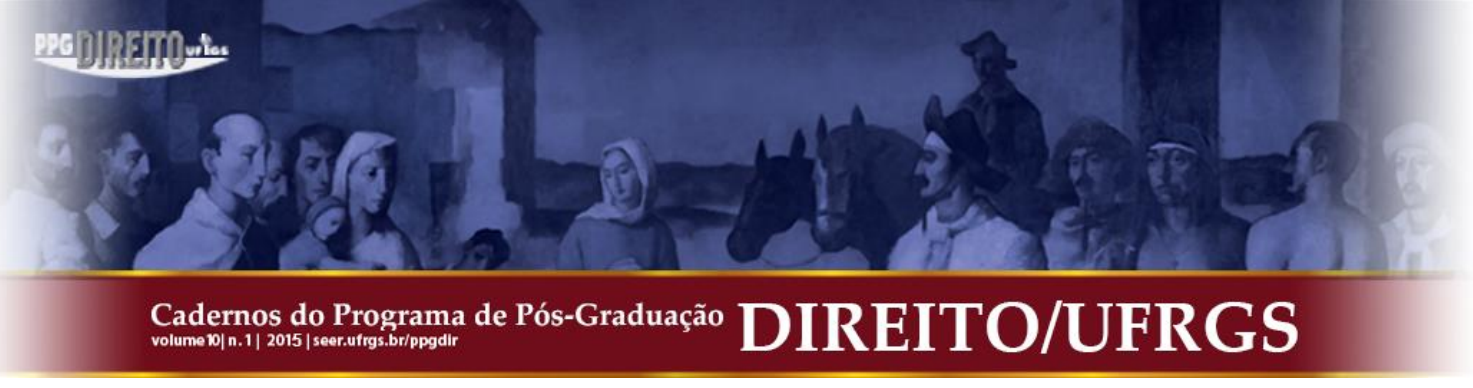

Pergunta-se agora se um investidor pode exigir uma indenização por danos devidos a um rating falho, em face da agência de rating em questão, a partir de um contrato com efeito protetivo de terceiros ou da culpa in contrahendo, sendo distinguidas duas situações, a do rating solicitado ("solicited rating") e a do rating não solicitado ("unsolicited rating”). No primeiro caso existe um contrato entre a agência de rating e o emitente, orientado à elaboração de um rating (notação). Se tal contrato pode desenvolver um efeito protetivo a favor de investidores, que adquirem ou vendem títulos de dívida deste emitente, há controvérsia na literatura jurídica alemã. De acordo com a jurisprudência do BGH, há, em geral, quatro condições para tal efeito protetivo: em primeiro lugar, o terceiro deve estar tão exposto aos perigos da relação obrigacional pretendida quanto o credor (proximidade do terceiro com a prestação - Leistungsnähe des Dritten). Em segundo lugar, o credor deve ter um interesse legítimo na proteção do terceiro (interesse na inclusão do terceiro - Einbeziehungsinteresse). Em terceiro lugar, o devedor precisa ter a possibilidade de reconhecer a existência do primeiro e do segundo requisitos no momento da constituição da relação obrigacional. E em quarto lugar, o próprio terceiro não deve ter nenhuma reivindicação de conteúdo comparável ${ }^{94}$. Quanto à responsabilidade da agência de rating frente os investidores, concordou-se largamente, a princípio, que o investidor, de acordo com o conteúdo do contrato de rating, entra em contato com a prestação pretendida na elaboração do rating, a qual a agência de risco prometeu fornecer ao emitente. Pois o rating deve oferecer ao investidor - este é o propósito principal do contrato de rating um auxílio à decisão relativa aos títulos financeiros deste emitente. Também se pode afirmar, sem maiores delongas, um interesse na inclusão por parte do emitente, porque detém obrigações de proteção frente aos investidores, que exigem a representação realista do risco de inadimplência do título ${ }^{95}$. Em contraste, existe disputa em relação à questão da possibilidade da agência de rating reconhecer, quando da emissão da notação, quais são as potenciais reivindicações dos demandantes creditícios, como, por exemplo, a proximidade da prestação. Alguns duvidam disto, porque o círculo de investidores não é limitado ao adquirente original da emis-

\footnotetext{
94 Para uma visão geral, BROX, Hans; WALKER, Wolf-Dietrich. op. cit., §33 II, p. 378 e ss. O entendimento expressado por Walker (p. 381), também compartilhado pelo BGH (BGHZ 56, 269 [271]), de que uma pretensão delitual de terceiro frente ao ofensor não é suficiente, é baseado em prazos de prescrição delitual mais curtos, anteriormente válidos (\$852 BGB versão antiga). Após a harmonização dos prazos de prescrição pela reforma do Direito das Obrigações Alemão de 2002, essa opinião se tornou desatualizada (PINGER, Winfried; BEHME, Caspar. Der Vertrag mit Schutzwirkung für Dritte als Rechtsgrundlage der Gutachterhaftung gegenüber Dritten. Juristische Schulung (JuS), Heft 8, 2008, p. 675-677).

${ }^{95}$ FORSCHNER, Julius. Die Haftung der Ratingagenturen. Jura Studium \& Examen, 2012, Ausgabe 1, p. 5-18. Cadernos do Programa de Pós-Graduação em Direito PPGDir./UFRGS | Edição Digital | Porto Alegre | Volume X | Número 1 | 2015 | P.68 - 93
} 


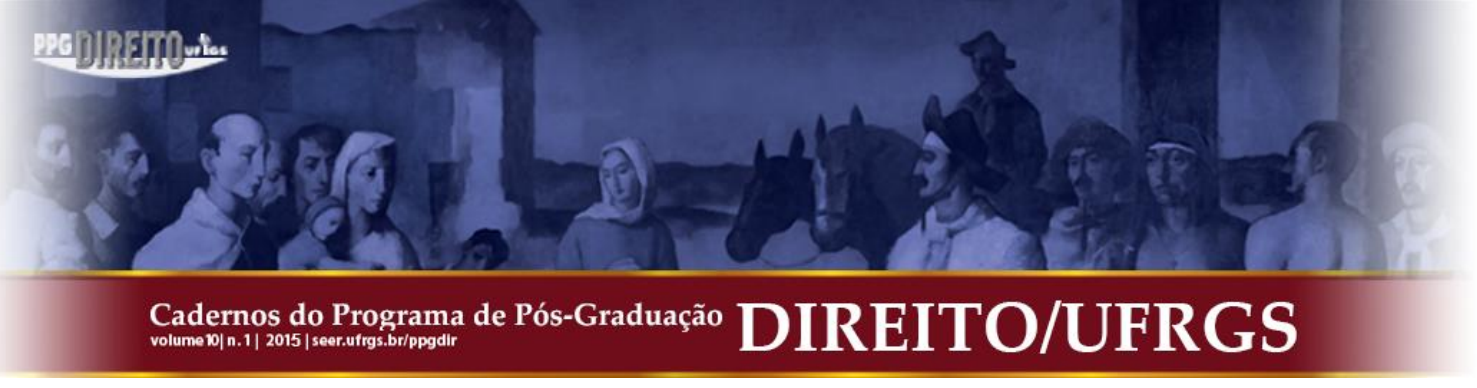

são, mas também inclui os investidores do mercado secundário ${ }^{96}$. Outros argumentam pelo reconhecimento do círculo de pessoas protegidas, pois as agências estariam cientes de que o propósito de suas notações visa à divulgação aos investidores ${ }^{97}$. Ainda não há uma clara jurisprudência superior sobre esta questão.

Quando o rating não foi solicitado pelo emitente ("unsolicited rating"), inexistindo uma conexão contratual entre a agência e o emitente, as reivindicações de indenização por danos ao investidor sobre a base de um contrato em favor de terceiro são de início desconsideradas. Assim, a questão que se coloca é se seria considerada uma responsabilidade baseada nesta relação jurídica, que pode ser realizada antes mesmo da celebração de contratos, designadamente na culpa in contrahendo. É de se considerar, neste contexto, a fase de tomada de decisão de um investidor antes da aquisição de títulos do emitente. Enquanto o contrato se refere a uma notação destes títulos, a aplicação da culpa in contrahendo, em seu ponto de partida, permanece aberta. Pois esta relação obrigacional também pode surgir, como já descrito, para pessoas que não são por si próprias partes contratuais (\$311, Abs. 3, S. 1 BGB). Em particular, pode um terceiro ser obrigado a indenizar danos, se assume para si um especial grau de confiança e, portanto, influencia significativamente a celebração do contrato ( $\$ 311$, Abs. 3, S. 2 BGB). Alguns querem a pronta aplicação do disposto no §311, Abs. 3, S. 2 BGB ao rating não solicitado ${ }^{98}$. O investidor confia - então foi dito - que o expert (a agência de rating) apresenta um parecer especializado independente. Em contraste, outros se sentem profundamente desconfortáveis pela aplicação dessa determinação, que faria com que a agência de rating suportasse imprevisíveis danos de terceiros ${ }^{99}$. Por isso, realçou-se que os ratings não são recomendação de investimento, mas simplesmente expressão de opinião a respeito do risco de inadimplência de títulos financeiros avaliados, havendo ausência do "impacto significativo" na celebração do contrato, requerido pelo $§ 311$, Abs. 3, S. 2 BGB ${ }^{100}$. Esta também é uma controvérsia ainda não decidida pela jurisprudência.

\footnotetext{
96 Vide ROSSET, Christophe. Haftung von Ratingagenturen. KCD Schriftenreihe. Band 2. Herausgegeben von Peter Ruhwedel. Essen: MA Akademie, 2013, p. 33.

${ }^{97}$ HAAR, Brigitte. op. cit. (NZG, 2010), p. 1281-1283.

${ }^{98}$ ROSSET, Christophe. op. cit., p. 35; WOJCIK, Karl-Philipp. op. cit. (NJW, 2013), p. 2385 e ss.

99 HENNRICHS, Joachim. Haftungsrechtliche Aspekte des Ratings. In: HÄUSER, Franz; HAMMEN, Horst et al (Hrsg.). op. cit., p. 875-890.

100 FORSCHNER, Julius. op. cit., p. 5-17. 


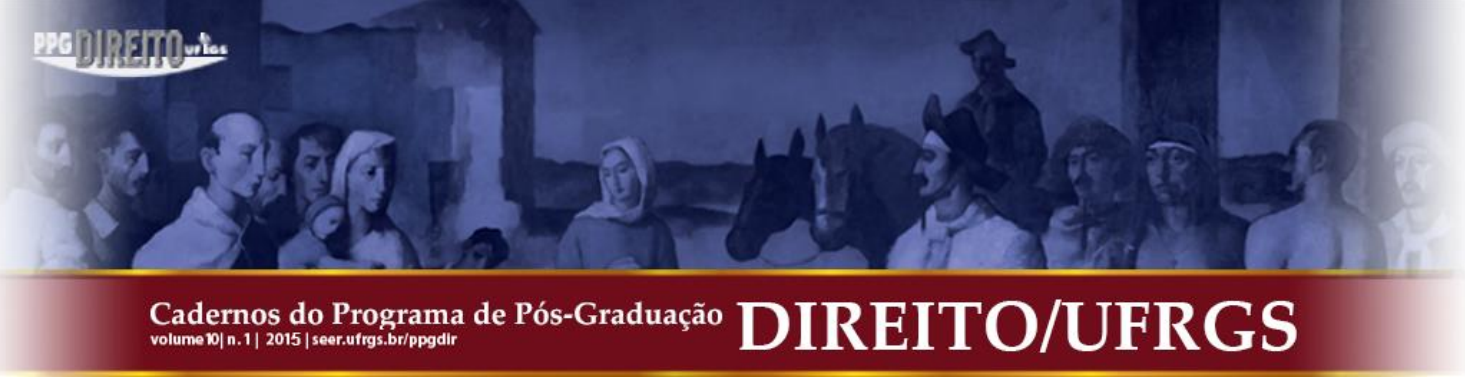

\section{Responsabilidade das Agências de Rating nos termos do Direito Europeu}

A dificuldade ${ }^{101}$ em encontrar uma base adequada para uma responsabilização perante os investidores nas legislações dos Estados-membros da União Europeia induziu o legislador europeu a providenciar, em maio de 2013, uma responsabilidade das agências de rating por causa de classificações insuficientes frente investidores em toda a Europa ${ }^{102}$. Mas isso desencadeou um problema para o poder legislativo. Nem toda avaliação de credibilidade de um devedor, que, em retrospectiva, prova-se demasiadamente otimista ou pessimista, é falha. Portanto, o legislador europeu teve que especificar quais más condutas das agências de rating resultam em uma responsabilidade. Por isso, o conjunto de fatos do artigo 35-A do regulamento europeu sobre agências de rating (Regulamento CE N 1060/2009, de 16 de setembro de 2009), o qual fundamenta uma responsabilidade das agências de rating, refere-se a um rol extensivo (anexo III), no qual se enumera em detalhes quando se assume uma conduta imprópria. Para esse propósito, inclui-se, por exemplo, a situação ocorrida quando a agência de rating falha ao eliminar conflitos de interesses, ou quando não garante que as classificações por ela emitidas sejam baseadas em uma análise minuciosa de todas as informações a ela disponíveis. No entanto, tal violação só gerará uma responsabilidade quando a agência de rating agiu intencionalmente ou de modo grosseiramente negligente. Este standard de falha pareceu adequado ao legislador, porque o conteúdo de um rating inclui a avaliação de fatores econômicos complexos e porque a aplicação de diferentes métodos de avaliação pode conduzir a classificações diferentes, nenhuma podendo ser considerada errada ${ }^{103}$. Além disso, a agência de rating só é responsável quando a conduta viciosa impacta a classificação ${ }^{104}$. Ademais, um investidor deve demonstrar que confiou nesse rating, com a devida diligência, ao tomar sua decisão de investimento (art. 35-A, Abs. 1 do Regulamento CE N 1060/2009, de 16 de setembro de 2009, sobre agências de rating). Deve-se ter em conta, no entanto, que especialmente os pequenos investidores não estão frequentemente em posição de analisar criticamente as classifi-

\footnotetext{
101 Também no direito alemão, vide HAAR, Brigitte. Nachhaltige Ratingqualität durch Gewinnabschöpfung? Zur Regulierung und ihrer Implementierung im Ratingsektor. Zeitschrift für Bankrecht und Bankwirtschaft (ZBB), Heft 3, 2009, p. 177-184.

102 WOJCIK, Karl-Philipp. op. cit. (NJW, 2013), p. 2385-2388; DUTTA, Anatol. Die neuen Haftungsregeln für Ratingagenturen in der Europäischen Union: Zwischen Sachrechtsvereinheitlichung und europäischem Entscheidungseinklag. Zeitschrift für Wirtschafts- und Bankrecht (WM), n. 37, 2013, p. 1729; WITTE, Jürgen Johannes; HENKE, Jessika. Status quo der Regulierung nach der neuen Rating-ÄnderungsVO. Der Betrieb (DB), Heft 40, 2013, p. 2257; HAAR, Brigitte. op. cit. (DB, 2013), p. 2489.

103 UNIÃO EUROPEIA, Regulamento (UE) N 462/2013, de 21 de maio de 2013, consideração 33.

104 A conduta viciosa precisa ter modificado o resultado do rating. WOJCIK, Karl-Philipp. op. cit. (NJW, 2013), p. 2385 e ss..
}

Cadernos do Programa de Pós-Graduação em Direito PPGDir./UFRGS | Edição Digital | Porto Alegre | Volume X | Número 1 | 2015 | P.68 - 93 


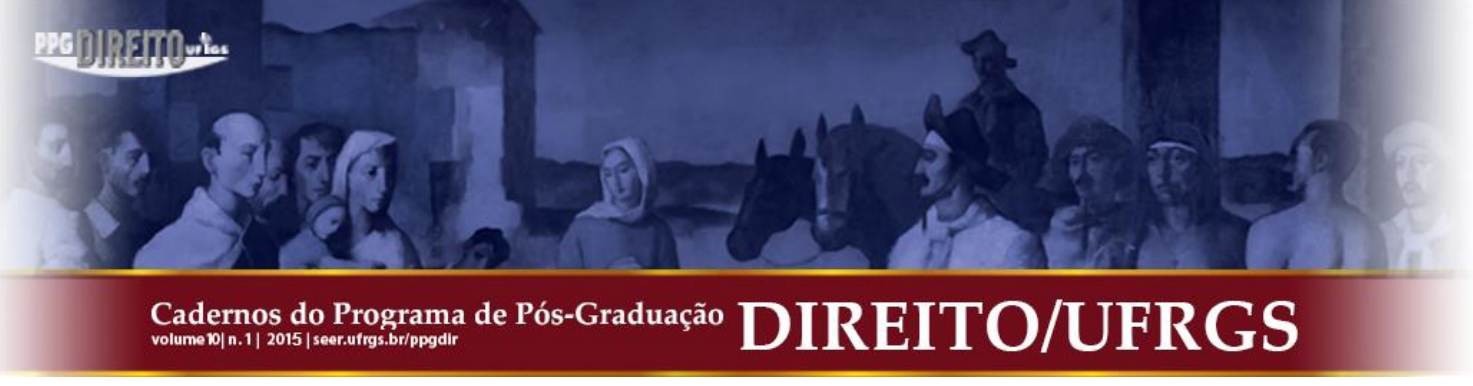

cações emitidas por uma agência de rating ${ }^{105}$. Outrossim, o investidor deve fornecer informações precisas e detalhadas sobre a má conduta da agência de rating (art. 35-A, Abs. 2 do Regulamento CE $\mathrm{N}^{\circ}$ 1060/2009, de 16 de setembro de 2009, sobre agências de rating). Obviamente, o juízo deve ponderar que o investidor possivelmente não tem acesso a informações que estão exclusivamente na esfera da agência de rating ${ }^{106}$. Por meio dessas limitações, a responsabilidade das agências de rating nos termos do direito europeu foi, não insignificantemente, restrita ${ }^{107}$. Isto, no entanto, não leva, de nenhum modo, a uma deterioração do status jurídico do investidor. Pois o regulamento europeu sobre agências de rating permite, aos Estados-Membros da união Europeia, a manutenção de regras nacionais sobre responsabilidade civil, que sejam mais favoráveis aos investidores (art. 35-A, Abs. 5 do Regulamento CE $\mathrm{N}^{\circ}$ 1060/2009, de 16 de setembro de 2009, sobre agências de rating) ${ }^{108}$.

\section{CONSIDERAÇÕES FINAIS}

O regulamento europeu sobre agências rating, revisado em maio de 2013, introduziu, pela primeira vez, uma base juridicamente segura para a responsabilidade das agências de rating na toda Europa. Com isto, o legislador europeu demonstrou bom senso, ao estabelecer altas exigências para a responsabilidade de uma agência de rating perante um investidor. Com razão, ele ponderou que a função das agências de rating, como intermediárias de informações, a serviço da eficiência dos mercados de capitais, não deveria ser indevidamente prejudicada por hipóteses de responsabilidade muito pungentes.

\section{REFERÊNCIAS}

ALEMANHA. Deutscher Bundestag. Drucksachen des Deutschen Bundestages. 14. Wahlperiode. Drucksache 14/745, de 12 de abril de 1999.

ASHTON, Peter Walter. A História da Elaboração do BGB Alemão. Revista da Faculdade de Direito Universidade Federal do Rio Grande do Sul, v. 31, 2013.

${ }^{105}$ UNIÃO EUROPEIA, Regulamento (UE) N ${ }^{\circ}$ 462/2013, de 21 de maio de 2013, consideração 36.

106 UNIÃO EUROPEIA, Regulamento (UE) N 462/2013, de 21 de maio de 2013, consideração 34.

107 Ver WOJCIK, Karl-Philipp. op. cit. (NJW, 2013), p. 2385-2388.

108 UNIÃO EUROPEIA, Regulamento (UE) N 462/2013, de 21 de maio de 2013, consideração 35.

Cadernos do Programa de Pós-Graduação em Direito PPGDir./UFRGS | Edição Digital | Porto Alegre | Volume X | Número 1 | 2015 | P.68 - 93 


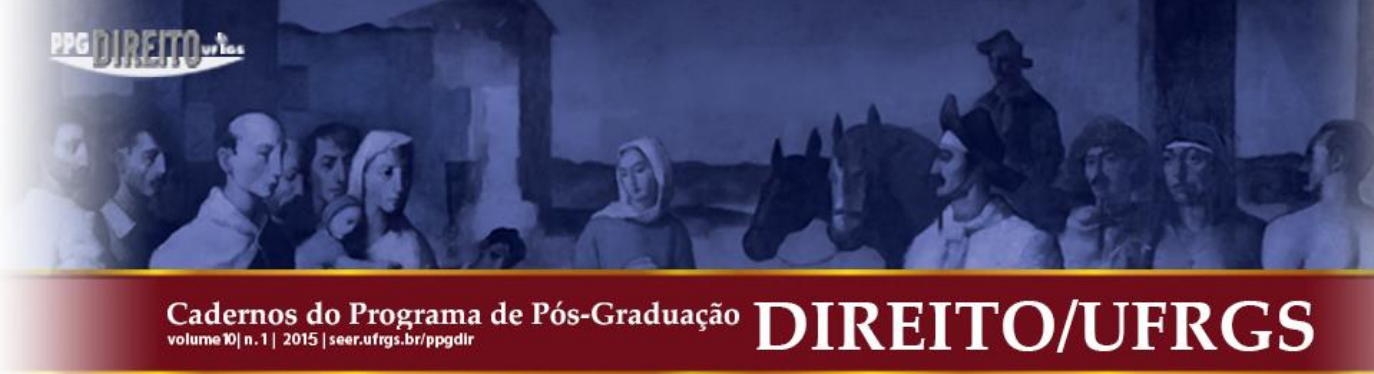

BAMBERGER, Heinz Georg; ROTH, Herbert. BGB. Beck'scher Online-Kommentar (1.11.2013). München: C. H. Beck, 2013.

BROX, Hans; WALKER, Wolf-Dietrich. Allgemeines Schuldrecht. 38. Auflage. München: C. H. Beck, 2014.

BURGHOF, Hans-Peter; SCHNEIDER, Johannes; WENGNER, Andreas. Der Informationsgehalt von Ratingänderungen für US- und europäische Unternehmen - Eine empirische Analyse. Zeitschrift für Bankrecht und Bankwirtschaft (ZBB), Heft 3, 2013.

CANARIS, Claus-Wilhelm. Die Reform des Rechts der Leistungsstörungen. Juristenzeitung (JZ), Band 56, 2001.

DUTTA, Anatol. Die neuen Haftungsregeln für Ratingagenturen in der Europäischen Union: Zwischen Sachrechtsvereinheitlichung und europäischem Entscheidungseinklag. Zeitschrift für Wirtschafts- und Bankrecht (WM), 2013.

ERMAN, Walter. BGB. 13. Auflage. Band 1. Herausgegeben von Harm-Peter Westermann, Barbara Grunewald und Georg Maier-Reimer. Köln: Otto Schmidt, 2011.

FIKENTSCHER, Wolfgang; HEINEMANN, Andreas. Schuldrecht. 10. Auflage. Berlin: De Gruyter, 2006.

FORSCHNER, Julius. Die Haftung der Ratingagenturen. Jura Studium \& Examen, Ausgabe 1, 2012.

FUCHS, Andreas; GEHRING, Kai. Kulturelle Faktoren beeinflussen die Länderratings vielfach unbewusst. Börsen-Zeitung, Frankfurt a.M., 12 fev. 2014.

GERNHUBER, Joachim (Hrsg.). Das Schuldverhältnis. Handbuch des Schuldrechts. Band 8. Tübingen: J. C. B. Mohr (Paul Siebeck), 1989.

HAAR, Brigitte. Neues zur Haftung von Ratingagenturen im Zuge der zweiten Novelle der RatingVerordnung (CRA III)? Der Betrieb (DB), Heft 44, 2013. 


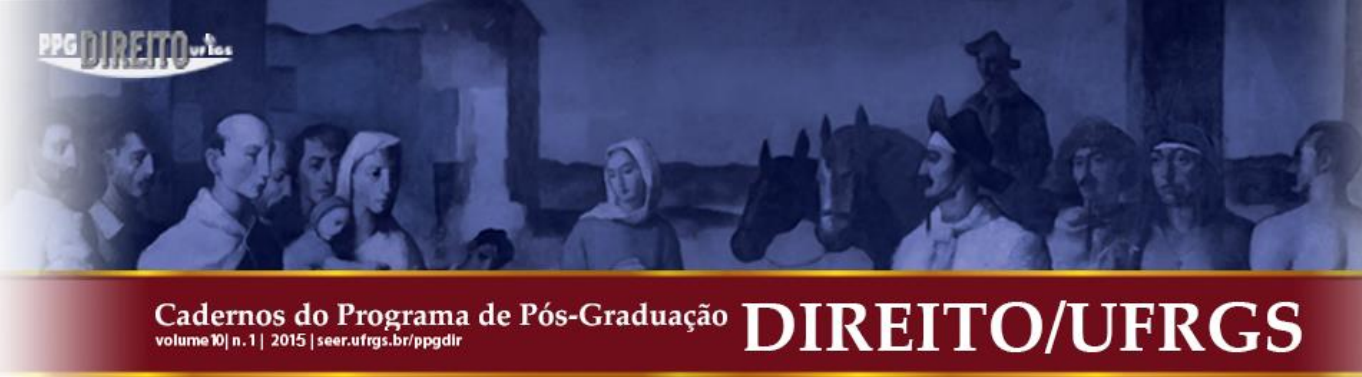

. Haftung für fehlerhafte Ratings von Lehman-Zertifikaten: Ein neuer Baustein für ein verbessertes Regulierungsdesign im Ratingsektor? Neue Zeitschrift für Gesellschaftsrecht (NZG), Heft 33, 2010.

Nachhaltige Ratingqualität durch Gewinnabschöpfung? - Zur Regulierung und ihrer Implementierung im Ratingsektor. Zeitschrift für Bankrecht und Bankwirtschaft (ZBB), Heft 3, 2009.

HÄUSER, Franz; HAMMEN, Horst et al (Hrsg.). Festschrift für Walther Hadding zum 70. Geburtstag. Berlin: De Gruyter, 2004.

HENNRICHS, Joachim. Haftungsrechtliche Aspekte des Ratings. In: HÄUSER, Franz; HAMMEN, Horst et al (Hrsg.). Festschrift für Walther Hadding zum 70. Geburtstag. Berlin: De Gruyter, 2004. Hoeren, Thomas (Hrsg.). Zivilrechtliche Entdecker. München: C. H. Beck, 2001.

JHERING, Rudolf von. Culpa in contrahendo oder Schadensersatz bei nichtigen oder nicht zur Perfection gelangten Verträgen. Jahrbücher für die Dogmatik des heutigen römischen und deutschen Privatrechts. Band IV. Herausgegeben von C. F. von Gerber und R. Jhering. Jena: Friedrich Mauke, 1861.

KASER, Max. Das römische Privatrecht. 2. Auflage. 1. Abschnitt. München: C. H. Beck, 1971.

KINDEREIT, Kai. Wer fühlt nicht, dass es hier einer Schadensersatzklage bedarf - Rudolf von Jhering und die „culpa in contrahendo“. In: Hoeren, Thomas (Hrsg.). Zivilrechtliche Entdecker. München: C. H. Beck, 2001.

LARENZ, Karl. Kennzeichen geglückter richterlicher Rechtsfortbildung. Karlsruhe: C. F. Müller, 1965.

Lehrbuch des Schuldrechts. 14. Auflage. Band I. Allgemeiner Teil. München: C. H. Beck, 1987.

LORENZ, Werner. Die Einbeziehung Dritter in vertragliche Schuldverhältnisse: Grenzen zwischen vertraglicher und deliktischer Haftung. Juristenzeitung (JZ), Band 15, 1960.

MUGDAN, Benno. Die gesammten Materialien zum Bürgerlichen Gesetzbuch für das Deutsche Reich. Band I. Berlin: R. v. Decker, 1899.

Cadernos do Programa de Pós-Graduação em Direito PPGDir./UFRGS | Edição Digital | Porto Alegre | Volume X | Número 1 | 2015 | P.68 - 93 


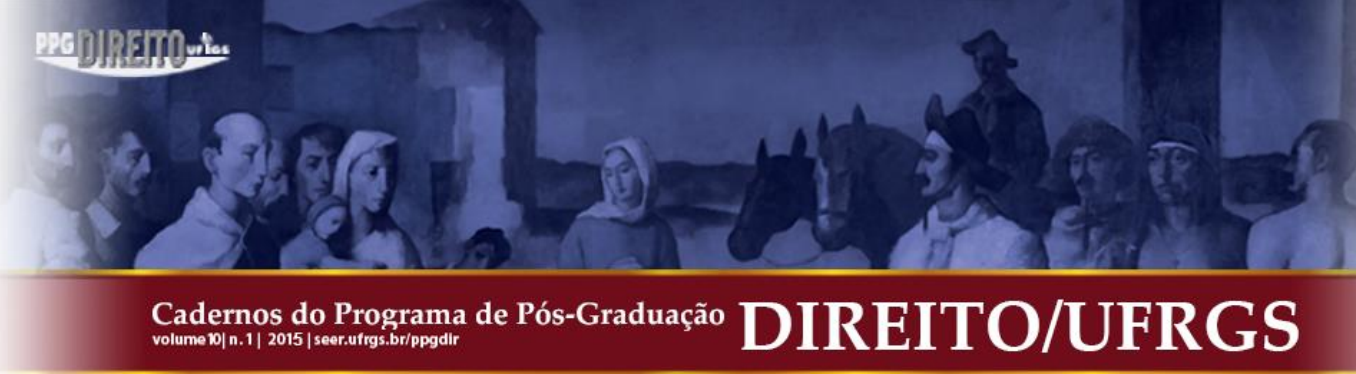

. Die gesammten Materialien zum Bürgerlichen Gesetzbuch für das Deutsche Reich. Band II. Berlin: R. v. Decker, 1899.

PINGER, Winfried; BEHME, Caspar. Der Vertrag mit Schutzwirkung für Dritte als Rechtsgrundlage der Gutachterhaftung gegenüber Dritten. Juristische Schulung (JuS), 2008.

ROSSET, Christophe. Haftung von Ratingagenturen. KCD Schriftenreihe. Band 2. Herausgegeben von Peter Ruhwedel. Essen: MA Akademie, 2013.

SÄCKER, Franz Jürgen; RIXECKER, Roland; OETKER, Hartmut (Hrsg.). Münchener Kommentar zum Bürgerlichen Gesetzbuch. 6. Auflage. Band 2. München: C. H. Beck, 2012.

(Hrsg.). Münchener Kommentar zum Bürgerlichen Gesetzbuch. 6. Auflage. Band 4 . München: C. H. Beck, 2012.

(Hrsg.). Münchener Kommentar zum Bürgerlichen Gesetzbuch. 4. Auflage. Band 2-A. München: C. H. Beck, 2003.

SOERGEL, Hans-Theodor. Bürgerliches Gesetzbuch mit Einführungsgesetz und Nebengesetzen: $B G B$. 13. Auflage. Band 5/3. Bearbeitet von Martin Gebauer, Walther Hadding, Walter Lindacher, Thomas lobinger, Thomas Pfeiffer sowie Klaus Schreiber. Stuttgart: Kohlhammer, 2010.

STAUDINGER, Julius von. Kommentar zum Bürgerlichen Gesetzbuch mit Einführungsgesetz und Nebengesetzen: BGB. Buch 2. Neubearbeitung von Rainer Jagmann und Volker Rieble. Redaktor Manfred Löwisch. Berlin: Walter de Gruyter, 2009.

. Kommentar zum Bürgerlichen Gesetzbuch mit Einführungsgesetz und Nebengesetzen: BGB. 10./11. Auflage. Teil 1D. Erläutert von Hubert Kaduk. Berlin: J. Schweitzer, 1978.

STOLL, Heinrich. Haftung für das Verhalten während der Vertragsverhandlungen. Leipziger Zeitschrift für Handels-, Konkurs- und Versicherungsrecht (LZ), Band 17, 1923.

VAN GELDER, Alfons. Schutzpflichten zugunsten Dritter im bargeldlosen Zahlungsverkehr? Zeitschrift für Wirtschafts- und Bankrecht (WM), 1995. 


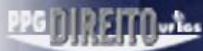

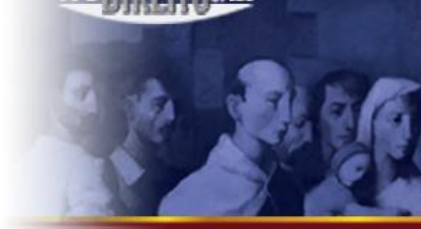 \\ Cadernos do Programa de Pós-Graduação volume 10|n.1| 2015 | seer.ufrgs.br/ppgdir}

WINDSCHEID, Bernhard. Lehrbuch des Pandektenrechts. 1. Auflage. Band 2. 1. Abteilung. Düsseldorf: Julius Buddeus, 1865.

WITTE, Jürgen Johannes; HENKE, Jessika. Status quo der Regulierung nach der neuen RatingÄnderungsVO. Der Betrieb (DB), Heft 40, 2013.

WOJCIK, Karl-Philipp. Zivilrechtliche Haftung von Ratingagenturen nach europäischem Recht. Neue Juristische Wochenschrift (NJW), Heft 33, 2013.

WOLF, Ernst. Allgemeiner Teil des bürgerlichen Rechts. 3. Auflage. Köln: C. Heymann, 1982. . Lehrbuch des Schuldrechts. Band 1. Allgemeiner Teil. Köln: C. Heymann, 1978.

ZIEGLER, Hans-Berndt. Verträge mit Schutzwirkung zugunsten Dritter? Marburg (Lahn): PhilippsUniversität Marburg, Dissertação, 1978.

ZSCHÄPITZ, Holger. Brasiliens Staatsschulden ruinieren die BRIC-Story. Die Welt, Berlin, 26 mar. 2014.

Submissão: 01/08/2015

Aceito para Publicação: 27/12/2014 
